\title{
PROJETO ESPAÇO RURAL SUSTENTÁVEL: ALIANDO PERMACULTURA, EDUCAÇÃO AMBIENTAL ESCOLAR E GESTÃO SUSTENTÂVEL DA PEQUENA PROPRIEDADE RURAL
}

\author{
Data de submissão: 27/10/2017 \\ Aceite: $17 / 07 / 2018$ \\ Ana Claudia da Rosa ${ }^{1}$ \\ Sonia Salete De Grandi² \\ Maria Goretti Rocha Farias ${ }^{3}$ \\ Lúcia Rejane da Rosa Gama Madruga ${ }^{4}$ \\ Marina de Alcântara ${ }^{5}$ \\ Marcia Helena dos Santos Bento ${ }^{6}$
}

\section{RESUMO}

Este artigo apresenta a experiência de interação entre o ensino superior e o ensino fundamental no Projeto Espaço Rural Sustentável, uma experiência concreta de educação ambiental desenvolvida por estudantes do sexto ano da Escola do Campo José Paim de Oliveira. O projeto foi desenvolvido com o apoio de pesquisadoras dos cursos de Administração e de Arquitetura, da Universidade Federal de Santa Maria (UFSM), e de um empresário com experiência na prática da permacultura. Na iniciativa, foi construída a maquete de uma propriedade rural sustentável, moldada por princípios permaculturais, a qual recebeu o primeiro prêmio da II Feira Municipal de Ciências, Tecnologia e Sustentabilidade da Rede Municipal de Ensino (RME) de Santa Maria/RS. O estudo apresentou abordagem qualitativa, junto da observação participante e do grupo focal. Os resultados apresentam o desenvolvimento do projeto, a confecção da maquete e as experiências relatadas pelos alunos. Em termos práticos, o projeto contribuiu com a prática pedagógica na escola e com a troca de experiências. Em aspectos teóricos, buscou-se a inserção da teoria de aprendizagem nos conhecimentos adquiridos e nas vivências sustentáveis, inserindo os princípios permaculturais na gestão sustentável de uma pequena propriedade rural e revelando o papel de articulação do administrador nas diferentes esferas da sociedade.

Palavras-chave: Educação ambiental, permacultura, aprendizagem vivencial, gestão da pequena propriedade rural.

\footnotetext{
1 Possui graduação em Administração pela Universidade Federal de Santa Maria UFSM, mestrado em Administração pela UFSM e doutorado em andamento em Administração pela UFSM. Santa Maria - Rio Grande do Sul. Brasil. E-mail: ana.claudiadarosaa@gmail.com 2 Possui graduação em Ciências pela Unijuí, com especialização no Ensino de Ciências pela Universidade Federal de Santa Maria. Atualmente é professora na Escola Municipal de Ensino fundamental José Paim de Oliveira, em Santa Maria. E-mail: degrandi.sonia@gmail.com 3 Possui graduação em Pedagogia pela Universidade Franciscana, UFN e mestrado em ensino de humanidades e linguagens pela UFN. Santa Maria - Rio Grande do Sul. Brasil. E-mail: go.rfarias@yahoo.com.br

4 Possui graduação em Administração pela Universidade Federal de Santa Maria, UFSM, mestrado em Engenharia de Produção pela UFSM e doutorado em Agronegócios pela Universidade Federal do Rio Grande do Sul, UFRGS. Santa Maria - Rio Grande do Sul. Brasil. E-mail: luciagm@ufsm.br

5 Possui graduação em Arquitetura e Urbanismo pela Universidade Federal de Santa Maria, UFSM, graduação pelo Programa Especial de Graduação de Formação de Professores para a Educação Profissional pela UFSM, e mestrado em Patrimônio Cultural pelo Programa de Pós-Graduação Profissionalizante em Patrimônio Cultural, PPGPPC. Santa Maria - Rio Grande do Sul. Brasil. E-mail: marinadealcantara@hotmail.com

6 Possui graduação em Formação de Professores para Educação Profissional pela Universidade Federal de Santa Maria, graduação em Ciências Contábeis pela UFSM, mestrado em Engenharia de Produção pela UFSM e doutorado em andamento em Administração pela UFSM. Santa Maria - RS. Brasil. E-mail: marciabento@politecnico.ufsm.br
} 


\section{INTRODUÇÃO}

Um dos aspectos que circundam a educação no ensino fundamental é a inserção da problemática ambiental no cotidiano escolar, tanto pelo cuidado com os impactos ambientais da própria escola quanto pela inserção do tema no processo educativo. Essa inserção precisa ocorrer não somente por meio das disciplinas, mas também por um viés interdisciplinar e transversal que possibilite ampliar os horizontes das questões ambientais para toda a comunidade (JACINTHO, 2011). Os comportamentos ambientalmente corretos devem ser aprendidos na prática, no cotidiano da vida escolar, contribuindo para a formação de cidadãos responsáveis. Para isso, a educação deve estar comprometida com o desenvolvimento sustentável, esclarecendo aos estudantes a importância da atitude de cada um para mudar a sua realidade, o que demanda às escolas o compromisso de mudança em prol da sustentabilidade (UNESCO, 2005; LEFF, 2015; UNESCO, 2002).

Vários são os aportes e os conceitos disponíveis para conduzir mudanças neste sentido. A permacultura, utilizada neste estudo como esquema conceitual, possui os instrumentos para tornar a educação ambiental mais eficaz e mais prática, já que representa uma forma de buscar respostas e soluções que fogem ao padrão hegemônico e às práticas comumente instituídas. Dessa forma, aproxima conhecimentos escolares, científicos e tradicionais, promovendo um engajamento efetivo para a solução de problemas ambientais e sociais no espaço rural. No ambiente escolar, os princípios permaculturais podem conectar as crianças aos fatos básicos que guiam os processos vitais e, quando aliados à gestão da propriedade rural, podem proporcionar o desenvolvimento sustentável de forma viável e segura para o pequeno agricultor familiar (SOARES, 1998;LOOS-SANTANA; LIMA, 2014).

Cabe ao educador, portanto, escolher o percurso que melhor promova a aprendizagem do estudante, por meio de um processo que proporcione o desenvolvimento de comportamentos compatíveis a soluções eficazes para a problemática ambiental. Nesse contexto, a educação ambiental é vista como um conjunto de fatores que levam a ações pedagógicas interdisciplinares e transdisciplinares para ocorrer efetivamente o processo ensino-aprendizagem (SOUZA, 2012).

Sob essa ótica, a experiência vivencial relatada neste artigo utilizou a permacultura como conceito base para promover a aprendizagem. Desse modo, a atual pesquisa objetiva relatar as etapas e os resultados no desenvolvimento de um projeto de uma propriedade rural sustentável, desenvolvida por estudantes do ensino fundamental de uma escola do campo, com auxílio de educadores, professores universitários e voluntários, os quais trouxeram o seu aporte de conhecimento e experiências para o locus escolar. A maquete foi apresentada pelos estudantes na II Feira Municipal de Ciências, Tecnologia e Sustentabilidade da Rede Municipal de Ensino (RME) de Santa Maria/RS, onde os estudantes foram premiados com o primeiro lugar.

\section{A EDUCAÇÃO AMBIENTAL NA ESCOLA}

A relação entre educação e desenvolvimento sustentável está presente nas discussões internacionais desde a primeira Conferência das Nações Unidas para o Meio Ambiente Humano (CNUMAD), que aconteceu em Estocolmo, Suécia, em 1972, e a primeira Conferência Intergovernamental sobre Educação Ambiental, realizada em Tbilisi, União Soviética, em 1977, onde foram estabelecidas as principais diretrizes para a Educação Ambiental no mundo. A educação é importante para a preparação de indivíduos para uma sociedade sustentável e, embora repre- 
sente o papel fundamental no desenvolvimento de uma consciência socioambiental, não é capaz de implementar a sustentabilidade sem que se tomem medidas concretas (LAUDER et al., 2006; JUCKER, 2002).

No Brasil, a Política Nacional de Educação Ambiental (PNEA), Lei 9.795/1999 (1999), propõe a inserção da Educação Ambiental (EA) em todos os níveis e modalidades do processo educativo como componente essencial e permanente da educação nacional. A PNEA prevê o desenvolvimento da EA como uma prática integrada, contínua e permanente, enfatizando que não deve ser implantada apenas como disciplina ou componente curricular específico (BRASIL, 2007). Em 2012, por meio de resolução específica, foram estabelecidas as Diretrizes Curriculares para a Educação Ambiental, reafirmando o seu caráter integrador.

O Programa Nacional de Educação Ambiental (ProNEA), um dos principais programas governamentais de EA, considera a educação ambiental como uma saída viável para a construção de um Brasil sustentável, entendido como uma nação socialmente justa e ambientalmente segura (BRASIL, 2005). A EA é uma dimensão essencial da educação fundamental, dizendo respeito a uma esfera de interações baseadas no desenvolvimento pessoal e social, ou seja, na relação com o meio (SAUVÉ, 2005).

Para sua efetivação como política transformadora, torna-se necessário instaurar um processo educativo ambiental capaz de potencializar, sinalizar e consolidar alternativas que rompam e transformem comportamentos, valores, atitudes, estilos de vida e formas de produção que são dominantes na sociedade (LOUREIRO, 2012). Esse processo, além de constituir um recurso que pode instigar nas pessoas o interesse pela preservação do meio em que vivem, alcançando, assim, uma sustentabilidade devida e correta, também apresenta potencial como um instrumento de gestão devido à sua capacidade de intervir no processo de construção social da realidade. Por meio do exercício de uma visão relacional e integrada do meio ambiente e do incentivo a uma cidadania ativa, o processo possibilita a conquista de espaços de participação e mobilização nas diferentes escalas de gestão (ROOS; BECKER, 2012; GUIMARÃES, 2001).

Dessa forma, a EA permite aos estudantes construírem noções de cidadania, pois a prática pedagógica é comprometida com a construção de valores, conceitos, habilidades e atitudes capazes de possibilitar o entendimento da realidade de vida e a atuação lúcida e responsável de atores sociais individuais e coletivos no ambiente (LOUREIRO, 2012). Frente à inserção da EA em todos os níveis de ensino, as soluções têm exigido cada vez mais o trabalho conjunto e integrado de profissionais das mais diferentes áreas, bem como a necessidade de uma visão criativa e o desenvolvimento de uma postura cooperativa nas escolas, de modo que já é rotina a elaboração de projetos interdisciplinares que auxiliam na promoção de valores em prol da sustentabilidade (FERRAZ, 2008).

Desenvolvem-se, assim, as competências e os valores que conduzirão os estudantes e a comunidade a repensar e a avaliar de outra maneira suas atitudes diárias e suas consequências no meio ambiente. Portanto, a EA é essencial para conscientizar as pessoas, uma vez que promove a execução de projetos, ideias, opiniões e trabalhos relacionados à sustentabilidade e à preservação ambiental. Assim sendo, este estudo utilizou a permacultura como aporte de conhecimento para integrar a EA na escola com a natureza do objeto de investigação, uma Escola do Campo, na tentativa de promover a consciência ambiental e sustentável diretamente aos estudantes e indiretamente aos seus familiares.

A permacultura é particularmente adequada para as escolas, pois oferece formas divertidas e sustentáveis de trabalhar o meio ambiente, uma vez que os estudantes que participam de atividades ligadas ao meio ambiente melhoram suas atitudes, provavelmente transformando- 
-se em adultos comprometidos com o seu meio (LEGAN, 2004). A ideia de realizar a educação ambiental através da permacultura para a promoção da sustentabilidade da escola vem sendo desenvolvida e experimentada em vários locais, como nas Eco-Schools em Portugal e no Chile, e, no Brasil, no Centro de Educação Profissional do Vale do Caí, no município de Feliz (RS), na Escola Autonomia (Florianópolis, SC), em algumas escolas municipais de São José do Cerrito (SC), Pirinópolis (GO) e em Porto Alegre (RS), atendidas pelo Programa de Educação Ambiental Contínua da Fundação da Gaia (FERRAZ, 2008).

O relato apresentado descreve o ciclo de aprendizagem de um grupo de estudantes que vivenciou a elaboração e a execução de um projeto de uma propriedade rural sustentável que teve a permacultura como esquema conceitual de suporte.

\subsection{PERMACULTURA E EDUCAÇÃO AMBIENTAL EM PROPRIEDADES RURAIS}

Criada pelos australianos Bill Molison e David Holmgren em meados da década de 1970, a permacultura é definida como "um conjunto de paisagens conscientemente desenhadas que reproduzem padrões e relações encontradas na natureza e que, ao mesmo tempo, produzem alimentos, fibras e energia em abundância e suficientes para prover as necessidades locais" (HOLMGREN, 2013, p. 33). Esse sistema foi moldado como uma síntese das culturas ancestrais sobreviventes, aliadas aos conhecimentos da ciência moderna, criando soluções e tecnologias ancoradas ao desenvolvimento sustentável, reunindo ideias, habilidades e modos de vida que devem ser reinventados com o objetivo de tornar as pessoas capazes de prover suas próprias necessidades, ao mesmo tempo em que garantem o capital natural para as necessidades futuras (HOLMGREN, 2013; JACINTHO, 2011).

Ancorada nos ombros da ecologia, a permacultura visualiza as relações ecológicas também como relações afetivas, pois se baseia nas interações dos seres vivos e não vivos entre si, vislumbrando como são afetados e como se afetam. Seu objetivo é melhorar a qualidade da afetividade entre as pessoas, e delas com o mundo e seus princípios, deixando clara a preocupação holística com as relações que envolvem o ser humano em seu habitat (LIMA, 2012; MORROW, 1993).

Os princípios permaculturais (MOLLISON; SLAY, 1998; LEGAN, 2004) podem ser aplicados em qualquer clima ou escala, sendo fundamentais para um bom projeto sustentável. São eles:

- Cada elemento é posicionado em relação a outro, de forma que se auxiliem mutuamente (tudo está conectado);

- Cada elemento executa muitas funções (visando as conexões);

- Cada função importante é apoiada por mais de um elemento (sobretudo as necessidades básicas devem ser supridas em duas ou mais formas);

- Planejamento eficiente do uso de energia para a casa ou o assentamento em zonas (de acordo com a quantidade ou frequência utilizada) e os setores (identificação de onde as energias - vento, água, luz, entram no espaço);

- Preponderância do uso de recursos biológicos sobre o uso de combustíveis fósseis;

- Reciclagem local de energias;

- Observação e imitação da natureza (trabalhar em conjunto com a natureza: sol, chuva, vento, padrões de elementos naturais, diversidade);

- Estabelecimento de ciclos de armazenagem e transporte de nutrientes, água, energia, retendo e usando antes que se percam; e

- Transformação dos problemas em soluções (criatividade). 
Um projeto permacultural envolve o planejamento, a implantação e a manutenção consciente de ecossistemas produtivos que tenham a diversidade, a estabilidade e a resistência dos ecossistemas naturais, resultando na integração harmoniosa entre as pessoas e a paisagem, provendo alimentação, energia, habitação, e outras necessidades materiais e não materiais de forma sustentável (SOARES, 1998).

Não se constitui como uma pedagogia e nem é este seu intuito, mas as ações, os valores, os princípios e os objetivos permaculturais apresentam uma visão concreta, reunindo ferramentas para uma prática educacional em prol da vida no planeta, de modo que, por fazer acontecer e por ter sucesso em seus projetos, permacultores de todo o mundo têm dado continuidade aos ensinamentos aprendidos (LOOS-SANTANA; LIMA, 2014).

Unindo o conhecimento secular às descobertas da ciência moderna, a permacultura também emerge como promotora do desenvolvimento sustentável integrado da propriedade rural, de forma viável e segura para o agricultor familiar. Além da diversificação da produção, ao contrário da agricultura convencional, busca equilibrar o uso dos recursos naturais, atuando ativamente no processo de transição para uma agricultura sustentável (TOMASETTO; LIMA; SHIKIDA, 2009; SOARES, 1998). Esse desenvolvimento sustentável nos planos econômico, social e ecológico pode ser atingido pela incorporação de tecnologias adequadas às diferentes condições locais, pela agregação de bens e serviços mais duráveis e, principalmente, por meio de uma nova visão de uso dos recursos, do aporte de energia ao sistema e da valoração do conhecimento local (FERRAZ; MARQUES; SKORUPA, 2003).

A gestão rural é um ramo da administração que utiliza as funções administrativas visando o uso eficiente dos recursos para obter resultados compensadores e contínuos na condução de uma empresa rural. Sua principal preocupação é conseguir a combinação mais lucrativa dos diversos fatores de produção, a fim de otimizar os resultados do agricultor. Essa gestão está relacionada com a habilidade de saber gerir recursos naturais - elementos que provêm da terra, da água, do clima e da vegetação natural -, humanos - pessoas que vivem e trabalham numa propriedade -, e de capital - bens e serviços criados, comprados ou prestados (SILVA, 2013).

Nesse sentido, a organização e a participação dos agricultores familiares no processo de desenvolvimento local devem buscar distribuição de renda e equidade social e, ao mesmo tempo, promover uma relação mais equilibrada com a natureza (TOMASETTO; LIMA; SHIKIDA, 2009). Sob essa perspectiva, a gestão da propriedade rural alicerçada nos princípios permaculturais transforma-se em instrumento para o estudo e a prática da EA no ambiente escolar, permitindo aos estudantes a transmissão desses conhecimentos e sua aplicação além do ambiente escolar.

A cultura da sustentabilidade e a cidadania ambiental são resultados de um fazer pedagógico que deve conjugar a aprendizagem a partir da vida cotidiana, ao passo que a EA centra-se em objetivos e ações para a construção de projetos nos quais se destaca a importância de contextos reais de vida e do cotidiano na construção de conhecimentos capazes de mudar a realidade. Assim, a agenda escolar deve ser trabalhada priorizando temas que surjam das demandas da comunidade (GUTIÉRREZ; PRADO, 2013), sendo, nesse sentido, a educação e a aprendizagem a chave para alcançar o desenvolvimento sustentável (BARTH; RIECKMANN, 2012).

\subsection{O CICLO DA APRENDIZAGEM VIVENCIAL}

Ao criar ambientes de aprendizagem onde os estudantes possam refletir e agir sobre a realidade, o sistema educacional terá maior oportunidade de atingir sua meta. O Ciclo de Aprendizagem Vivencial (CAV) (KOLB; RUBIN; MCINTYRE, 1978) aborda o desenvolvimento de atitudes, 
de conhecimentos e de habilidades em um ciclo onde o conhecimento é formado a partir da transformação da experiência vivida pelo indivíduo. O processo de aprendizagem é tanto ativo quanto passivo, tanto concreto quanto abstrato, podendo ser concebido como um ciclo de quatro estágios: (1) experiência concreta; (2) observação e reflexão; (3) formação de conceitos abstratos e generalizações; e (4) hipóteses a serem testadas no futuro que levarão a novas experiências, conforme ilustrado na Figura 1.

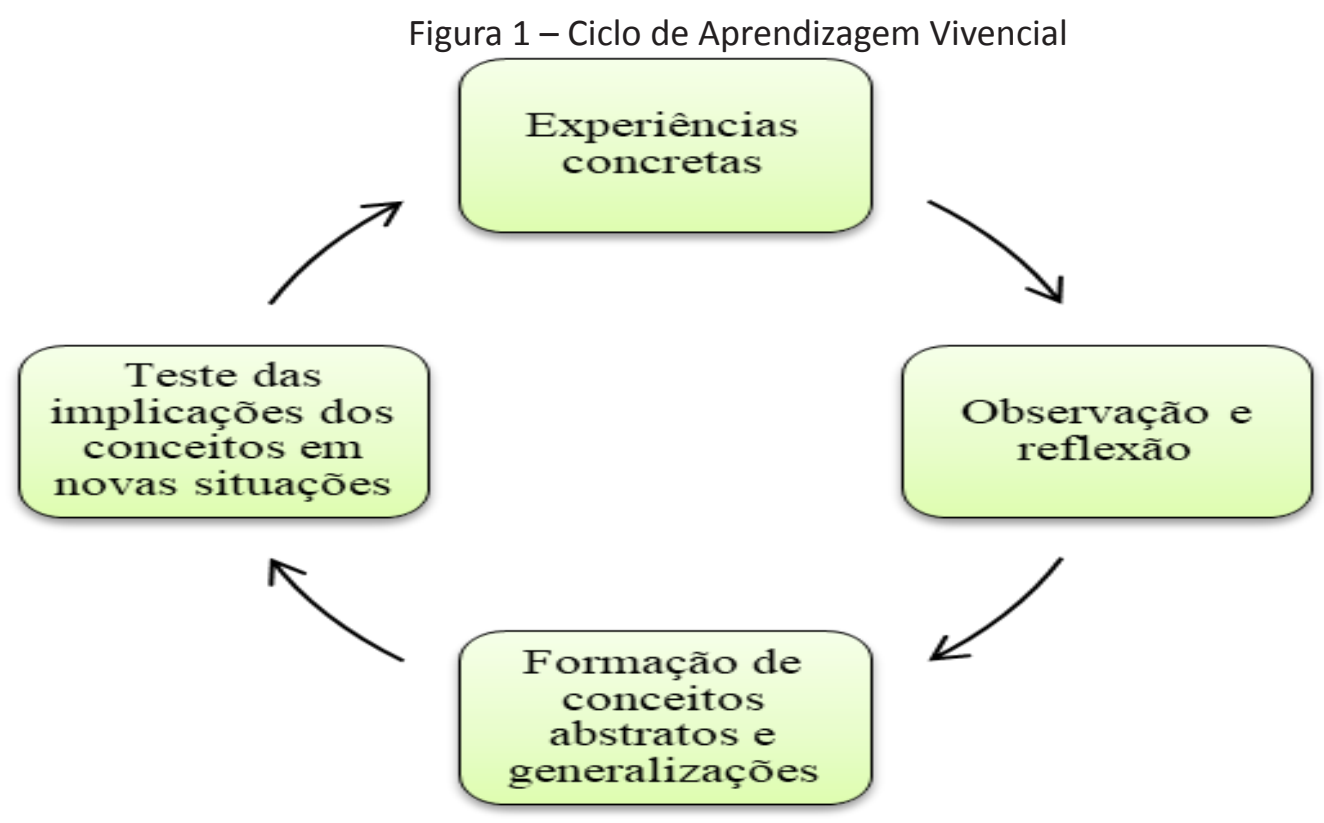

Fonte: adaptado de Kolb, Rubin e McIntyre (1978, p. 38).

O CAV repete-se frequentemente, apresentando uma direção governada pelas necessidades sentidas e pelos objetivos da pessoa, de modo que os estilos de aprendizagem se tornam altamente individuais, tanto na direção quanto no processo. $O$ estímulo do ciclo vivencial de aprendizagem pode emergir por meio de práticas em sala de aula ou de metodologias de ensino mais inovadoras, como a coordenação do autodesenvolvimento através da participação na atividade desenvolvida, a realização de questionamentos e de pesquisas que contribuam para o processo de aprendizagem, e a superação das paredes da sala de aula, a fim de ser parte da realidade do estudante e dos meios com os quais ele interage (GONÇALO; BITENCOURT; MANCIA, 2003).

A EA, por sua vez, não pode perder de vista a necessidade de participação do cidadão na busca de alternativas e soluções aos graves problemas ambientais, sejam eles locais, regionais ou globais (CASTRO; CANHEDO JR, 2005). Desse modo, promover a interação entre EA, permacultura e gestão de propriedade rural sustentável, por meio de um projeto, se mostrou uma vivência instigadora para o grupo de profissionais envolvidos, uma vez que se visualizou uma ação potencial para o desenvolvimento das atitudes, dos conhecimentos e das habilidades dos estudantes envolvidos em prol da sustentabilidade e de todos os conceitos que a circundam. 


\section{ASPECTOS METODOLÓGICOS}

O Projeto Espaço Rural Sustentável foi desenvolvido na Escola Rural José Paim de Oliveira, com o objetivo de engajar os estudantes em atividades sustentáveis no ambiente escolar. Uma dessas atividades envolveu a confecção de uma maquete que reproduzia uma propriedade rural sustentável, possibilitando a participação dos estudantes do sexto ano na II Feira Municipal de Ciências, Tecnologia e Sustentabilidade da Rede Municipal de Ensino (RME) de Santa Maria/RS. O desenvolvimento da maquete contou com a ajuda de colaboradores da Universidade Federal de Santa Maria (UFSM): duas pesquisadoras do curso de Administração; uma professora e quatro alunas do curso de Arquitetura; um técnico agrícola (professor da escola); quatro professores da escola rural; e um voluntário com vivência na construção de projetos permaculturais.

O percurso metodológico se deu em três momentos: (i) elaboração do projeto e confeç̧ão da maquete, e (ii) relato dos estudantes sobre as experiências vivenciadas. No desenvolvimento e elaboração do projeto, fez-se uma observação participante (MOREIRA, 2004). Os instrumentos utilizados incluíram acompanhamento das rotinas dos estudantes e professores, visitas à escola, reuniões e entrevistas com estudantes e especialistas, relatos dos professores, orientações aos professores, estudo dos temas envolvidos e anotações. Essa etapa culminou com a elaboração do projeto que foi encaminhado para a Feira de Ciências.

Após a elaboração do projeto, elaborou-se a maquete. Para tanto, estavam envolvidos os acadêmicos e a professora de arquitetura, assim como o voluntário com experiência em projetos permaculturais. Esses experts orientaram os estudantes tanto na confecção dos elementos quanto na definição do escopo, projetando a distribuição de cada elemento na maquete construída pelos estudantes sob a orientação da professora coordenadora da atividade na escola. Os estudantes visitaram uma propriedade rural sustentável próxima à escola e assistiram a uma palestra realizada pelo técnico agrícola.

As experiências vivenciadas pelo grupo na confecção da maquete, assim como a participação na Feira Municipal, foram relatadas por meio de um grupo focal (MORGAN, 1997) realizado na escola, no qual os estudantes participantes interagiram a partir do tópico sugerido pelas pesquisadoras. O grupo focal contou com doze estudantes e uma professora. A coleta dos dados foi realizada em uma sala de aula da própria escola durante o horário de aula, com duração aproximada de quarenta minutos. Os estudantes se dispuseram na sala em forma de círculo, e os dados foram coletados em formato de áudio e de gravação de vídeo, sendo analisados, posteriormente, por meio da técnica de análise de conteúdo (BARDIN, 2014).

\section{RESULTADOS: ELABORAÇÃO DO PROJETO E MAQUETE}

A elaboração do projeto envolveu os estudantes em todas as fases, sendo o tema definido a partir de questionamentos em sala de aula sobre alguma atividade ou conteúdo de seu interesse que envolvesse a sustentabilidade e que contemplasse o locus de vivência dos estudantes. Na sequência, foram desenvolvidas diversas atividades no Projeto Espaço Rural Sustentável, conforme as quatro etapas do Ciclo de Aprendizagem Vivencial necessárias a um projeto para envolver os estudantes (FERRAZ, 2008). Na identificação e planejamento, foram feitas análises de algumas realidades locais em que estão inseridas as famílias da comunidade e, nessa etapa, os professores da escola entraram em contato com as pesquisadoras da UFSM para que auxiliassem na elaboração da maquete. 
Uma vez definido o escopo da maquete, partiu-se para a implementação do projeto. Nesse momento, foram realizados estudos e pesquisas nas disciplinas ministradas na escola, as quais versaram sobre temas como: formas de energia, possibilidades de reaproveitamento do espaço e de todo o material produzido em uma propriedade rural, tratamento de resíduos, agroflorestas, coleta de água da chuva, telhado verde, fossa ecológica, produção e geração de rendas alternativas em pequenas propriedades rurais, compostagem, problemas ambientais e sociais, reciclagem, dentre outros elementos que constituíram a maquete.

Foram demonstradas várias possibilidades para a construção de uma propriedade rural sustentável (princípios permaculturais) com o máximo de reaproveitamento possível e com um baixo investimento econômico. Sob essa perspectiva, desenvolvendo o projeto de educação para o ambiente, a escola promoveu aos estudantes e à comunidade uma compreensão fundamental acerca dos problemas existentes, fruto da presença humana no ambiente, bem como sobre a sua responsabilidade e o seu papel crítico como cidadãos na construção de um mundo melhor.

Após diversas visitas, encontros e reuniões entre as pesquisadoras da UFSM, o proprietário da chácara sustentável e os professores da escola, foram definidos todos os elementos que deveriam estar presentes na maquete. Na etapa seguinte, no ateliê da universidade, a professora de Arquitetura, com o auxílio de quatro alunas, deu início à confecção da base da maquete, utilizando materiais reaproveitados dos resíduos de maquetes desenvolvidas no Curso de Arquitetura. A partir da base da maquete, a professora do Curso de Arquitetura realizou uma visita à escola e, juntamente com os estudantes do sexto ano, confeccionou a maquete.

Durante a confecção, os estudantes mostraram-se dispostos a aprender e a empregar seus conhecimentos sobre sustentabilidade na propriedade rural que estava sendo moldada na maquete. A elaboração da maquete seguiu os princípios da permacultura, e todos os elementos foram elaborados de modo a otimizar os recursos advindos da natureza, sendo a maquete dividida em zonas permaculturais. Essas zonas são áreas mais ou menos concêntricas de intensidade de uso, as quais descrevem o poder e a ciência das pessoas que trabalham a partir do ponto focal, uma morada, conforme exposto na Figura 2.

Figura 2 - Zonas de permacultura

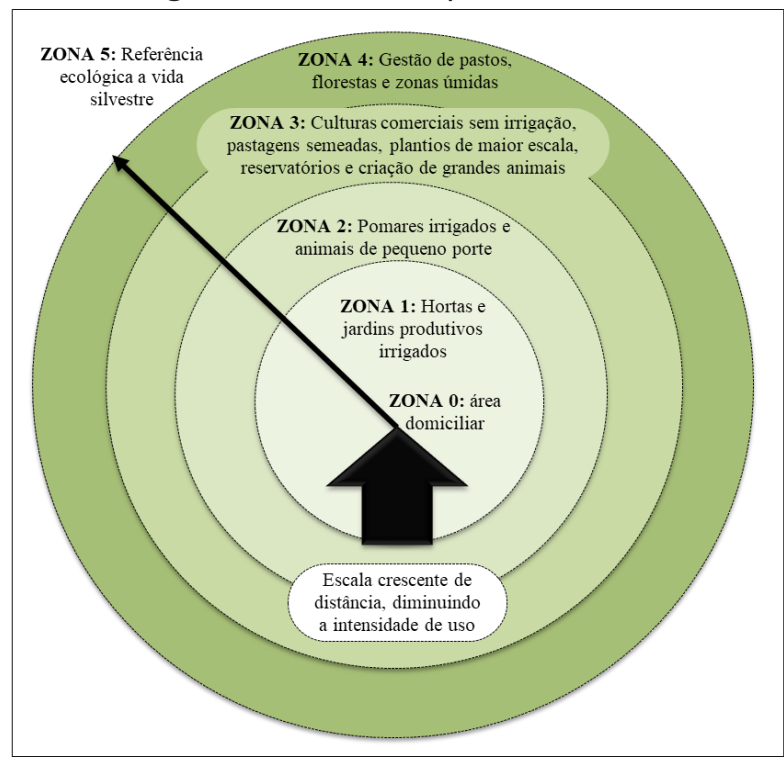

Fonte: adaptado de Holmgren (2013, p.233). 
Com base nessas zonas permaculturais propostas por Holmgren (2013), as zonas da maquete foram constituídas pelos seguintes elementos:

- Zona 0: casa sustentável e fossa ecológica;

- Zona 1: horta e estufa;

- Zona 2: pomar, galinheiro para criação de galinhas, chiqueiro para criação de porcos e galpão para guardar insumos agrícolas;

- Zona 3: plantação das culturas de cana, mandioca, feijão e milho;

- Zona 4 e Zona 5: rio, mata nativa e animais silvestres.

A maquete buscou refletir as irregularidades do terreno, a fim de demonstrar de forma mais próxima da realidade os aspectos da propriedade rural sustentável, além de elencar elementos e culturas comuns às propriedades da região da escola. Além disso, destaca-se que, na Zona 0 , a localização da casa foi planejada de modo a aproveitar a luz proveniente do período da manhã, sendo que a casa sustentável contou com telhado verde para melhor aproveitamento e retenção do calor, bem como uma cisterna para reaproveitamento da água da chuva. Ainda buscou-se mostrar a preservação da mata nativa na Zona 4 e a preservação das matas ciliares no rio e na estrada. A Fotografia 1, abaixo, apresenta a maquete elaborada:

\section{Fotografia 1 - Maquete propriedade rural sustentável}

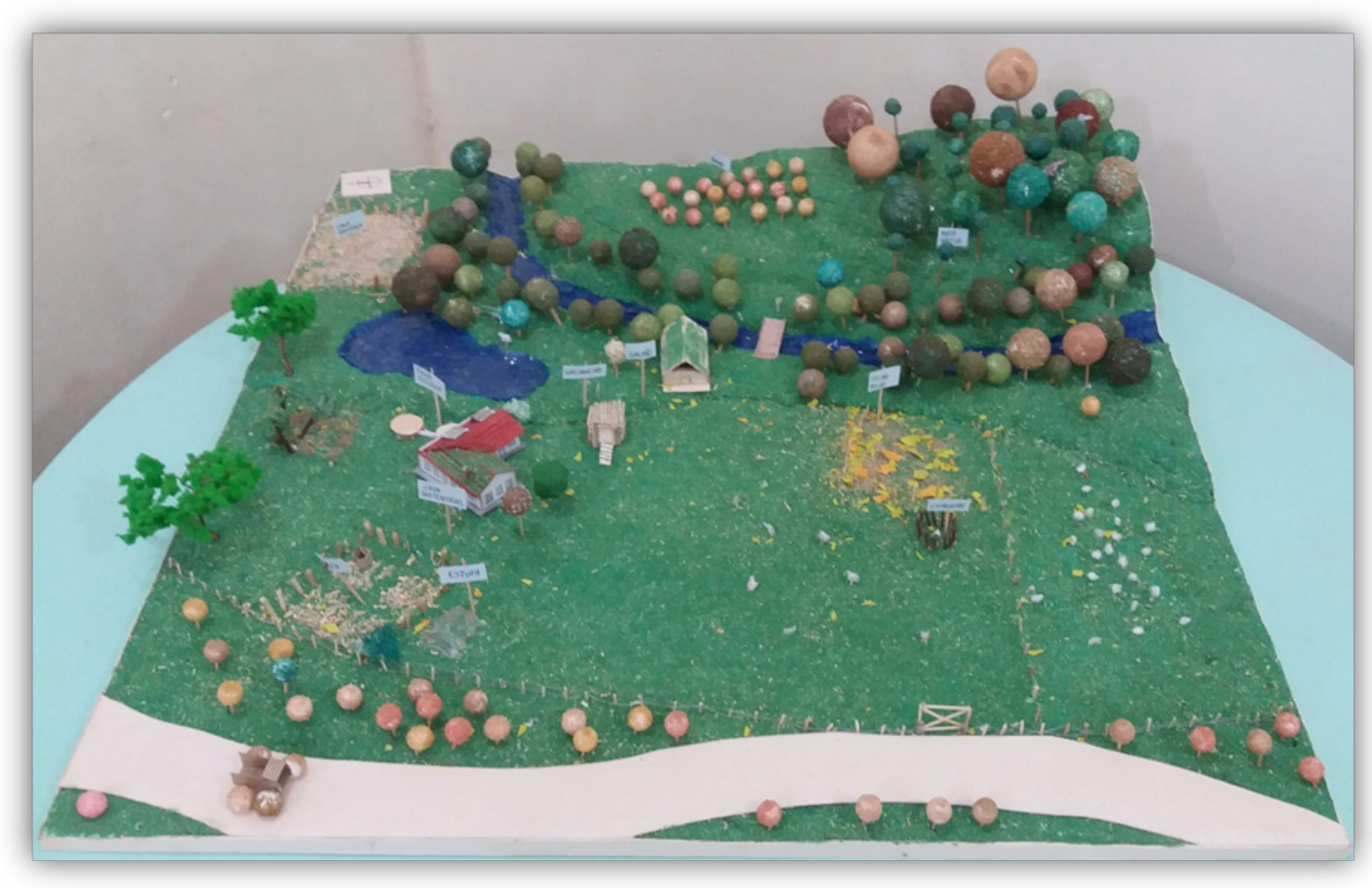

Fonte: Rosa (2016).

A seguir, a Fotografia 2 revela os detalhes das Zonas 0 (casa sustentável e fossa ecológica), Zona 1 (horta e estufa), Zona 2 (pomar, galinheiro para criação de galinhas, chiqueiro para criação de porcos e galpão para guardar insumos agrícolas) e Zona 3 (plantação das culturas de cana, mandioca, feijão e milho). 
Fotografia 2 -Detalhe das Zonas 0, 1, 2 e 3

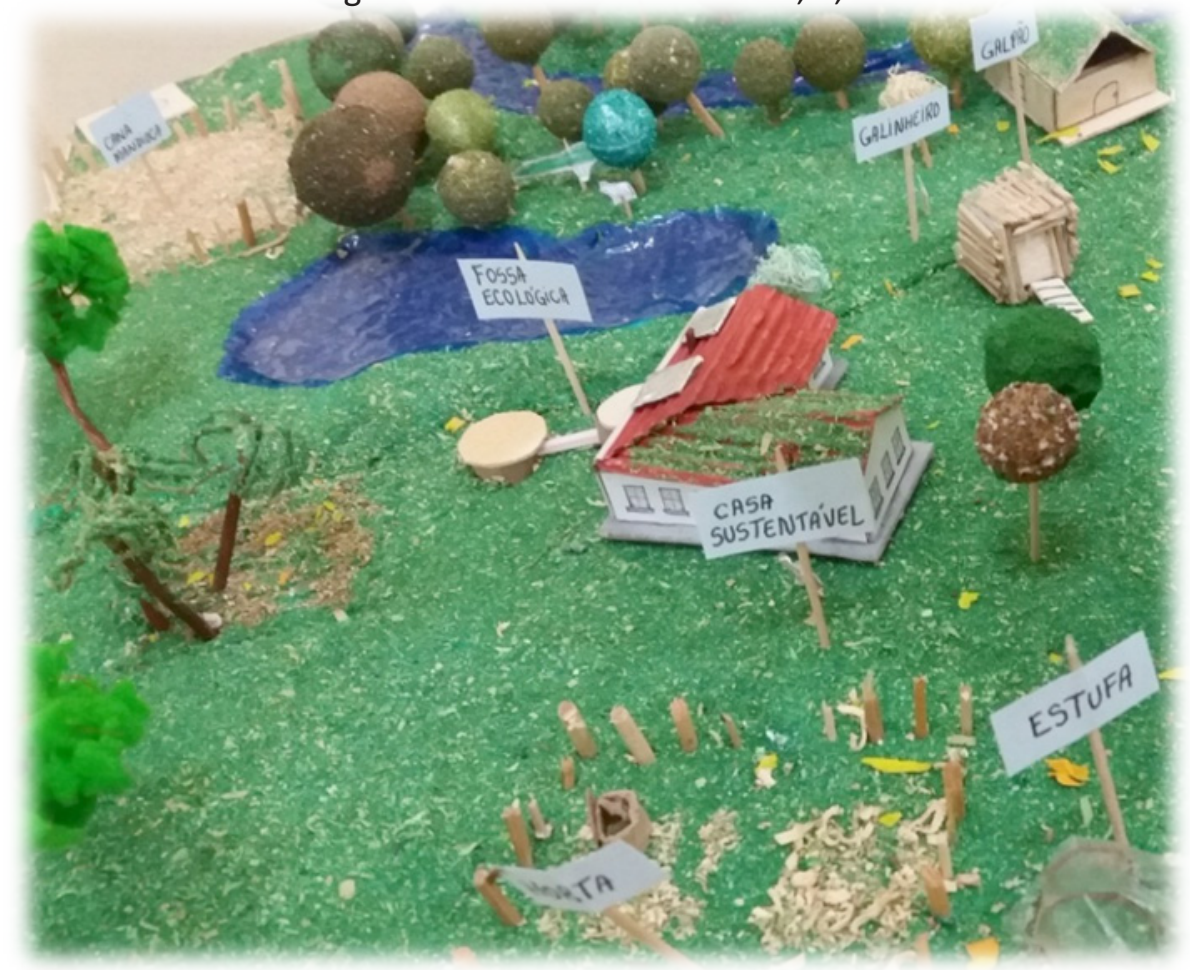

Fonte: Rosa (2016).

A Fotografia 3 expõe de forma detalhada as Zonas 4 e 5 (rio, mata nativa e animais silvestres):

Fotografia 3 -Detalhe das Zonas 4 e 5

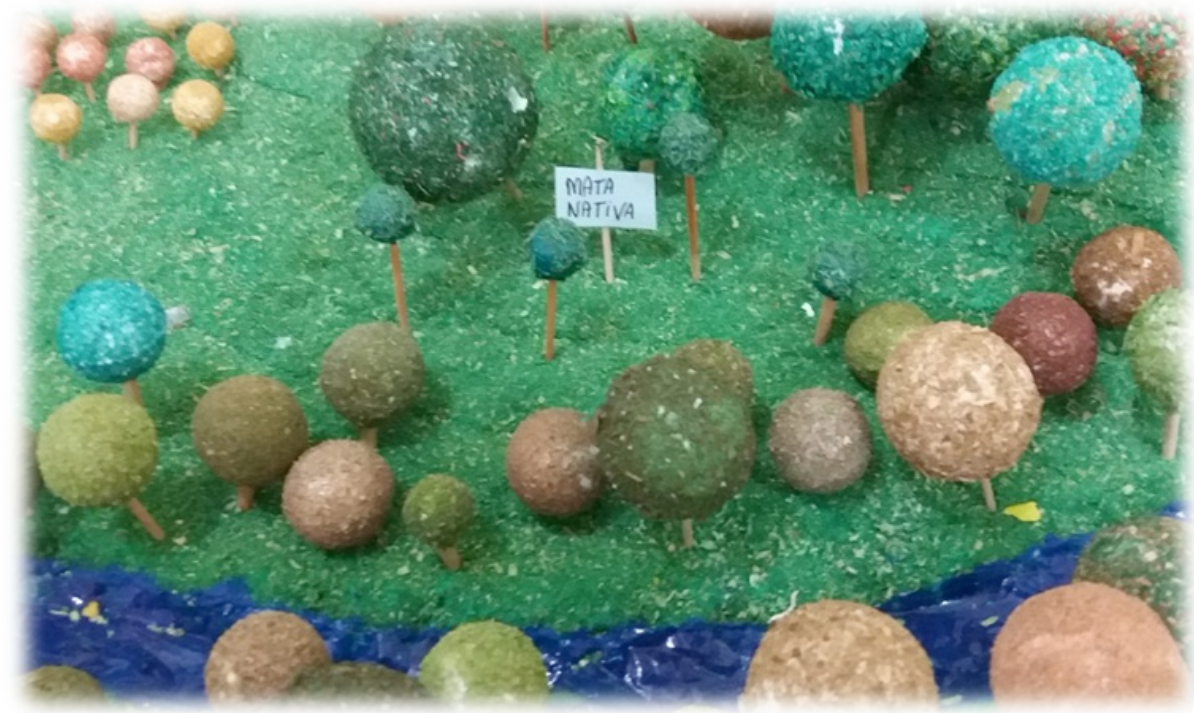

Fonte: Rosa (2016).

Após finalizar a confecção da maquete, foram escolhidos os quatro estudantes responsáveis pela apresentação na Feira Municipal e, assim, juntamente com o auxílio dos professores 
da escola, eles planejaram e ensaiaram a sua apresentação. A Feira foi realizada no dia 25 de novembro de 2016, no Centro Desportivo Municipal (CDM). Os estudantes do sexto ano conquistaram o primeiro lugar na categoria Anos Iniciais, algo inédito na escola. Esse fato superou as expectativas de todos os envolvidos no projeto, revelando a importância do trabalho em equipe e do engajamento de todos, bem como a importância da integração entre universidade e escola, pois o conhecimento extrapolou a sala de aula, indo ao encontro da comunidade.

$O$ resultado desse projeto possibilitou à escola valorizar o trabalho dos estudantes, que podem sentir-se capazes e orgulhosos da sua intervenção, estimulando a confiança e a solidariedade por meio de práticas desenvolvidas no projeto, que podem fazer a diferença na qualidade ambiental da escola e da comunidade (FERRAZ, 2008).

\subsection{O RELATO DA EXPERIÊNCIA DOS ESTUDANTES ENVOLVIDOS NO PROCESSO}

O processo de aprendizagem está descrito pelo CVA: (1) experiência concreta; (2) observação e reflexão; (3) formação de conceitos abstratos e generalizações; e (4) hipóteses a serem testadas no futuro, as quais levarão a novas experiências.

A experiência concreta no desenvolvimento do projeto destaca-se a partir da confecção da maquete e da participação na Feira Municipal. Os estudantes foram indagados sobre o que mais gostaram na experiência, sobre as atividades desenvolvidas, sobre as dificuldades no trabaIho em grupo e sobre a ajuda dos professores no processo.

[...] o que eu mais gostei, na verdade, foi tudo, que a gente sem estudo não seria ninguém [...] [ESTUDANTE C].

Um objetivo trazido pelos estudantes foi expor a realidade do homem do campo para as pessoas residentes na cidade, revelando a importância da preservação das áreas rurais:

[...] pras pessoas que moram na cidade pra elas terem uma noção que o homem no campo pode fazer [ESTUDANTE B].

Os estudantes afirmaram que o trabalho em grupo foi bom, pois eles se ajudaram no desenvolvimento da maquete, revelando que apenas um ou dois colegas não manifestaram interesse em ajudar. Eles também destacaram a importância da ajuda dos professores. Além disso, contaram que a escolha dos estudantes que iriam apresentar a maquete na Feira Municipal ocorreu pela própria disposição de quatro deles, sem gerar conflitos entre a turma.

Sobre a experiência de apresentar na Feira, os estudantes falaram que gostaram, acreditando terem explicado bem, e dois deles revelaram que gostaram mais de apresentar na Feira Municipal do que na própria escola, pois na Feira eles tiveram contato com outras pessoas, mostrando o trabalho desenvolvido na escola, o que pode ser verificado na seguinte fala:

[...] eu gostei desse trabalho porque ele ensinou outras pessoas que tavam lá né, e também a professora disse pros outros colegas que tavam brabo em perder pra uma maquete, a professora disse que ali que a maquete não tinha só uma maquete, a maquete tinha todo um trabalho que foi feito, pensado num futuro pra nós poder fazer [...] [ESTUDANTE A].

Conforme a fala do estudante, ressalta-se a complexidade da elaboração da maquete, que envolveu diversas pessoas e elencou inúmeros elementos que podem ser inseridos em uma propriedade rural. Além disso, a turma afirmou ser a primeira vez que realizaram um trabalho 
que envolvesse a confecção de uma maquete. Um dos estudantes destacou também a busca pela atenção da comissão avaliadora dos trabalhos na hora da apresentação da maquete.

Indo ao encontro das falas dos estudantes, destaca-se que, para a educação ambiental ser transformadora, ela deve estar articulada com a mudança social, transformando a pedagogia em uma prática política, com uma cooperação entre educadores/as e outros sujeitos culturais, criando espaços críticos de aprendizagem dentro e fora da escola. Isso porque as mudanças não ocorrerão de cima para baixo, mas sim com a participação direta de estudantes/as, professores/ as comunidade e meio ambiente, em uma dinâmica complexa (TRISTÃO; RUSCHEINSKY, 2012; GIROUX, 2003).

A importância dessa cooperação e participação de todos os indivíduos envolvidos no processo ficou clara com o resultado obtido, ou seja, com a conquista do primeiro lugar na Feira. Sobre isso, uma fala dos estudantes chamou a atenção: "[...] foi legal porque a gente é a turma menor do colégio e a gente conseguiu trazer um troféu pra escola [...]" [ESTUDANTE B]. Diante disso, a professora também afirmou:

[...] quando foi anunciado o primeiro lugar, foi muito bonito. [...] Ficamos sérios, nos olhando. Eu disse: "vamos lá, nós temos que receber o prêmio". [...] Então foi muito bom assim, foi maravilhoso. Eu acho que a fala deles, a postura, o carinho de todos [...]. E, claro, toda a estrutura, ficou bela a maquete, ficou muito bonita a nossa maquete [...] [PROFESSORA].

A professora também ressaltou o sotaque característico da zona rural mais presente em dois estudantes, aspecto que chamou a atenção da comissão avaliadora de forma positiva durante a apresentação.

Os estudantes também salientaram um aspecto negativo na Feira: um menino estava debochando da apresentação da maquete, o que, contudo, motivou a união para continuarem defendendo suas ideias durante a apresentação, ignorando o fato ocorrido. Além disso, os estudantes também trouxeram aspectos de aprendizagem, falando que eles aprenderam e ensinaram com a experiência, indo ao encontro da observação e da reflexão.

Sobre a observação, a reflexão e a formação de conceitos, as pesquisadoras indagaram aos estudantes sobre os conceitos aprendidos, questionando se eles poderiam ensinar algo para outras pessoas a partir da experiência. Os estudantes falaram sobre preservar a natureza, aproveitar o que a natureza oferece:

[...] não gastar tanta luz, que se as pessoas fizessem o que foi aprendido não haveria tanta poluição [...] [ESTUDANTE A].

Com as falas dos estudantes, pode-se observar a conscientização acerca dos conceitos de sustentabilidade e da preservação da natureza durante o desenvolvimento da maquete, revelado também pela seguinte fala de um dos estudantes, quando questionados sobre o que seria ser sustentável:

[...] economizar faz bem pro bolso da gente e pra natureza também né, não seria a gente começa a gastar e gastar, e aquele gasto, e consome lixo e isso e aquilo e a natureza fica cada vez mais suja, e o meio ambiente mais sujo pras pessoas né [...] [ESTUDANTE A].

Ao questionar se os estudantes poderiam ensinar algo com os conhecimentos que adquiriram por meio da experiência, eles afirmaram que poderiam ensinar sobre a importância da preservação das matas ciliares: 
[...] eu acho que a gente pode ensinar sobre os rios, da água, aqui tem rios tão bonitos e é tudo sem árvore em volta, tem erosão. Se tem uma sanga bonita ou um rio, a gente deve falar pras pessoas não arrancarem as árvores [...] [ESTUDANTE A].

Sob essa ótica, a educação escolar não deve promover somente esse conhecimento, mas deve incentivar habilidades e valores que orientarão e motivarão os estudantes rumo a estilos de vida sustentáveis. Desse modo, no que diz respeito ao teste das implicações dos conceitos em novas situações, alguns estudantes levaram a experiência para casa, contando-a para seus familiares: pais, tios, tias, avós.

Os estudantes relataram que levarão os aprendizados para fazer em casa, como a fossa ecológica. Um deles já aplicou um dos aprendizados no seu dia-a-dia fazendo uma compostagem em casa. Esse estudante revelou ainda que sua mãe acreditava ser necessário dispender um alto custo para "colocar em prática" todas as ideias propostas pela maquete, afirmando que "[...] fazer sustentabilidade, dá muito trabalho [...]" [ESTUDANTE C]. Outro estudante também apontou um problema diferente: o espaço necessário para inserir soluções sustentáveis. Nesse momento, a professora afirmou que, por exemplo, o que eles viram sobre a fossa ecológica não era "tão caro assim". Uma das pesquisadoras referiu-se também ao uso de material reaproveitável.

Quando indagados sobre o que eles podem mudar a partir dos novos conhecimentos adquiridos, um dos estudantes lembrou a questão do lixo, falando que as pessoas não devem jogar lixo, mas recolhê-lo. Ademais, um segundo estudante mencionou a questão da dengue, afirmando que não se deve deixar água parada. Desse modo, esse estudante trouxe uma implicação importante dos conceitos aprendidos, indo da aplicação em uma propriedade rural para cuidados com a saúde. Dessa maneira, observa-se que a educação escolar deve estar comprometida com o desenvolvimento sustentável, deixando claro aos estudantes a importância de cada um tomar alguma atitude para mudar a sua realidade (UNESCO, 2005).

Mais ainda, eles lembraram que podem trazer para a própria escola os conceitos aprendidos, como, por exemplo, uma horta para os estudantes aprenderem a cultivar para o consumo próprio. A professora também destacou:

[...] vocês estão no sexto ano, então tem o sétimo, oitavo e nono ano pra ficar na escola. Muitas coisas aqui na escola, nós temos que mudar: captação da água, uma coisa que vocês têm que batalhar, lixo, a fossa, fazer uma estrutura sustentável [...]. Vamos trabalhar pra isso, vamos começar a mudar, começar a partir de agora, vamos trabalhar pra que as coisas que foram aprendidas lá sejam aplicadas na escola. Trocar o sistema elétrico por placa solar, fazer esse levantamento, ver essas possibilidades [...] [PROFESSORA].

Ressalta-se a importância da incorporação dos princípios sustentáveis no dia-a-dia da própria escola, pois os comportamentos ambientalmente corretos devem ser aprendidos na prática, no cotidiano da vida escolar, contribuindo para a formação de cidadãos responsáveis. Desse modo, a cidadania ambiental e a cultura da sustentabilidade serão, necessariamente, o resultado do fazer pedagógico que conjugue a aprendizagem a partir da vida cotidiana (GUTIÉRREZ; PRADO, 2013; LEFF, 2015). 


\section{CONSIDERACOÕES FINAIS: O APRENDIZADO E SUAS CONTRIBUIÇỐES}

"Quem ensina, aprende ao ensinare
quem aprende, ensina ao aprender"

Freire (p.12, 2014).

A realização e a participação no Projeto Espaço Rural Sustentável possibilitaram diversos ensinamentos a todos os envolvidos, desde os participantes do projeto até a comunidade. No relato do planejamento da confecção da maquete, foram evidenciadas todas as etapas envolvidas no processo, onde foram elencados os elementos utilizados na maquete com base nos princípios permaculturais (HOLMGREN, 2013) e a superação das expectativas com a conquista do primeiro lugar na categoria Anos Inicias na Feira Municipal.

Por meio do projeto, destaca-se o papel do administrador nas mais diversas esferas da sociedade, como articulador para promoção da sustentabilidade, pois as pesquisadoras da área, ao serem contatadas pelos professores da escola, buscaram a ajuda e a conexão de diversos profissionais, tornando possível a elaboração e a confecção da maquete.

A pedagogia da educação ambiental fomenta a participação através da cooperação, da valorização do potencial criativo humano e da interconexão de diversas áreas do saber, assumindo a complexidade da realidade socioambiental (FERRAZ, 2008). Essa educação é, potencialmente, um instrumento de gestão por sua capacidade de intervir no processo de construção social da realidade (GUIMARÃES, 2001), por meio do incentivo às práticas ambientalmente adaptadas e a uma cidadania ativa que possibilite a ampliação da participação e mobilização popular.

O presente estudo, em termos práticos, contribuiu com a prática pedagógica no ambiente escolar e possibilitou a troca de experiências entre profissionais das mais diversas áreas de conhecimento. A vivência relatada trouxe ganhos práticos não só para os estudantes, mas para a sociedade, uma vez que os resultados extrapolaram os muros da escola, já que os estudantes levaram para seus lares os conhecimentos adquiridos.

Este projeto apresentou, também, resultados teóricos, em que as contribuições ao desenvolvimento da ciência são evidenciadas ao se buscar a inserção da teoria de aprendizagem vivencial (KOLB, RUBIN e MCINTYRE, 1978) nos conhecimentos adquiridos e nas vivências sustentáveis, como também a inserção dos princípios permaculturais na gestão sustentável de uma pequena propriedade rural, revelando o importante papel de articulação do administrador nas diferentes esferas da sociedade.

Sobre os aspectos que poderiam ser melhorados, aponta-se as questões didático/metodológicas próprias de pesquisas qualitativas, tanto em termos dos sujeitos envolvidos, quanto dos aspectos captados pelas pesquisadoras no decorrer da pesquisa, como por exemplo, na realização do grupo focal, onde poucos estudantes se manifestaram, impossibilitando um relato completo das experiências vivenciadas por eles.

As sugestões adentram o campo da educação voltada para a sustentabilidade no ambiente escolar. Pretende-se ampliar a perspectiva de desenvolvimento do ensino da sustentabilidade nesta área. Ressalta-se que está em andamento um projeto de pesquisa do qual fazem parte as pesquisadoras da universidade, cujo objetivo é organizar um banco de ações práticas que possibilitem o ensino da sustentabilidade em sala de aula, buscando subsídios em experiências e vivências semelhantes, desenvolvidas em outras instituições de ensino.

As pesquisadoras desejam continuar o desenvolvimento das atividades na escola, aplicando os conhecimentos adquiridos na confecção da maquete. Além disso, almeja-se ampliar o 
projeto e levar as discussões e os conhecimentos acerca das vivências sustentáveis para as demais escolas da Rede Municipal de Ensino de Santa Maria/RS. Ressalta-se, enfim, que o papel das pesquisadoras da área de administração tratou da articulação entre os contatos desses diversos profissionais, visando encontros e elaboração do projeto da maquete.

\section{REFERÊNCIAS}

BARDIN, L. Análise de Conteúdo. Lisboa: Edições 70, 2014.

BARTH, M.; RIECKMANN, M. Academic staff development as a catalyst for curriculum change towards education for sustainable development: an output perspective. Journal of Cleaner Production, v. 26, p. 28-36, 2012.

BRASIL, Lei no 9.394 de 20 de dezembro de 1996. Estabelece as diretrizes e bases da educação nacional. Diário Oficial da República Federativa do Brasil, Brasília, DF, 20 dez. 1996. Disponível em: <https://www.planalto.gov.br/ccivil_03/Leis/L9394.htm> Acesso em: 10 dez. 2016

. Lei no 9.795, de 27 de abril de 1999.Política Nacional de Educação Ambiental. Diário Oficial da República Federativa do Brasil, Brasília, DF, 27 abr. 1999. Disponível em: <http://www. planalto.gov.br/ccivil_03/leis/L9795.htm> Acesso em: 10 dez. 2016.

. Ministério do Meio Ambiente. Programa Nacional de Educação Ambiental ?] ProNEA. 3. ed. Brasília: Editora do Ministério do Meio Ambiente, 2005.

- Vamos cuidar do Brasil: conceitos e práticas em educação ambiental na escola. Brasília: MMA, MEC, 2007.

CASTRO, M. L. de; CANHEDO JR., S. G. Educação Ambiental como Instrumento de Participação. In: PHILIPPI JR., A.; PELICIONI, M. C. F. (Ed.). Educação ambiental e Sustentabilidade. Barueri: Manole, p. 381-400, 2005.

FERRAZ, J. M. G.; MARQUES, J. F.; SKORUPA, L. A. Indicadores de sustentabilidade em agroecossistemas. Embrapa meio ambiente: Jaguariúna, SP. 2003.

FERRAZ, M. L. C. P. Sustentabilidade das Escolas Municipais de Ensino Fundamental: Estudo de caso em Ubatuba, Estado de São Paulo, Brasil. São Paulo, 2008. Tese (Doutorado em Ciência Ambiental) - Programa de Pós-graduação em Ciência Ambiental, Universidade de São Paulo.

FREIRE, P. Pedagogia do oprimido. 34. ed. São Paulo: Paz e Terra, 2014.

GIROUX, H. A. Atos impuros: a prática política dos estudos culturais. Porto Alegre: ARTMED, 2003.

GONÇALO, C.; BITENCOURT, C.; MANCIA, L. O Desenvolvimento de Competências: uma experiência baseada na proposta andragógica e na aprendizagem vivencial. In: ENCONTRO NACIONAL DOS CURSOS DE PÓS-GRADUAÇÃO EM ADMINISTRAÇÃO, 27., São Paulo, 2003, Anais... São Paulo: ANPAD, p. 1-18. 
GUIMARÃES, M. Educação Ambiental e a Gestão para a Sustentabilidade. In: SANTOS, José Eduardo dos; SATO, Michele (Org.). Contribuição da Educação Ambiental à Esperança de Pandora. São Carlos/SP: RIMA, 2001, p. 183-195.

GUTIÉRREZ, F.; PRADO, C. Ecopedagogia e Cidadania Planetária. 3. ed. São Paulo: Cortez, 2013.

HOLMGREN, D. Permacultura: princípios e caminhos além da sustentabilidade. Tradução: Luzia Araújo. Porto Alegre: Via Sapiens, 2013.

JACINTHO, T. R. dos S. Educação para sustentabilidade: turismo ecopedagógico no centro de Permacultura Asa Branca e implantação de um espaço permacultural na Escola Classe Jardim Botânico. Brasília, 2011. Dissertação (Mestrado em Engenharia Florestal) ? Departamento de Engenharia Florestal, Universidade de Brasília.

JUCKER, R. "Sustainability? Never heard of it" Some basics we shouldn't ignore when engaging in education for sustainability. International Journal of Sustainability in Higher Education, v. 3, n. 1, p. 8-18. 2002.

KOLB, D. A.; RUBIN, I. M.; MCINTYRE, J. M. Psicologia Organizacional: uma abordagem vivencial. São Paulo: Atlas, 1978.

LAUDER, H. et al. Education, globalization and social change. Oxford University Press: Oxford, 2006.

LEFF, E. Saber ambiental: sustentabilidade, racionalidade, complexidade, poder. 11 ed. Petrópolis, RJ: Vozes, 2015.

LEGAN, L. Escola Sustentável: ecoalfabetizando pelo ambiente. Imprensa Oficial, São Paulo, 2004.

LOOS-SANTANA, H.; LIMA, C. S. Representações de crianças sobre a natureza a partir de uma perspectiva ecológica afetivamente ampliada da vida. Educação (UFSM), v. 39, p. 201, 2014.

LOUREIRO, C. F. B. Trajetória e fundamentos da educação ambiental. 4 ed. São Paulo: Cortez, 2012.

MOLLISON, B.; SLAY, R. M. Introdução à permacultura. Brasília: MA/SOR/PNFC, 1998.

MOREIRA, D. A. Pesquisa em Administração: Origens, usos e variantes do método fenomenológico. Revista de Administração e Inovação, v. 1, n. 1, 2004.

MORGAN, D. L. Focus group as qualitative research. In: MORGAN, D. L. Qualitative Research Methods Series. London: Sage Publications, cap. 1, p. 6-17, 1997.

MORROW, R. Permacultura Passo a Passo. Trad. André Luis Jaeger Soares. Austrália: Kangaroo Press, 1993. 
ROOS, A.; BECKER, E. L. S. Educação ambiental e sustentabilidade. REGET, v. 5, n. 5, p. 857 - 866, 2012.

SAUVÉ, L. Educação ambiental: possibilidades e limitações. Educação e pesquisa, v. 31, n. 2, p. 317-322, mai./ago. 2005.

SILVA, R. A.G. da. Administração Rural Teoria e Pratica. 3 ed. Curitiba: Juruá, 2013.

SOARES, A. L. J. Conceitos básicos sobre permacultura. Brasília: MA/SDR/PNFC, 1998.

SOUZA, M. A. da S. C. Análise do processo ensino e aprendizagem de Educação Ambiental em microbacia hidrográfica. Jaboticabal, 2012. Tese (Doutorado) - Faculdade de Ciências Agrárias e Veterinárias, Universidade Estadual Paulista.

TOMASETTO, M. Z. C.; LIMA, J. F.; SHIKIDA, P. F. A. Desenvolvimento local e agricultura familiar: o caso da produção de açúcar mascavo em Capanema - Paraná. Interações, v. 10, n. 1, p. 21-30, jan./jun. 2009.

TRISTÃO, M.; RUSCHEINSKY, A. A educação ambiental na transição paradigmática e os contextos formativos. In: RUSCHEINSKY, A. (Org.). Educação ambiental: abordagens múltiplas. 2. ed. Porto Alegre: Penso, p. 289-312, 2012.

UNESCO. Contributing to a more sustainable future: quality education, life skills and education for sustainable development.2002. Disponível em: <http://unesdoc.unesco.org/images/0014/ 001410/141019e.pdf> Acesso em: 10 mai. 2017.

UNESCO. Década da educação das Nações Unidas para um desenvolvimento sustentável, 20052014: documento final do esquema internacional de implementação, 2005. Disponível em: <http://unesdoc.unesco.org/images/0013/001399/139937por.pdf> Acesso em: 03 mar. 2017. 